\title{
NOVEL METHOD OF IMPLEMENTING SPIROMETER USING
} ANDROID

\author{
Karthikeyan. $A^{1}$, Khaleelu Rahman. $M^{2}$, Velmurugan. $A^{3}$ \\ ${ }^{1,2}$ UG Scholar, ${ }^{3}$ Assistant Professor, Department of Biomedical Engineering, Sri Ramakrishna Engineering College, \\ Vattamalaipalayam, Coimbatore, Tamilnadu, India
}

\begin{abstract}
This paper identifies a robust approach in the design and development of portable spirometer for modern healthcare. The nature of lung disorders which can be tested physiologically consists of the conditions such as asthma, chronic bronchitis and emphysema. These conditions may be related to COPD (Chronic obstructive Pulmonary Disease) which is then identified as the third leading contributor related to cigarette smoking. The existing spirometer system is that they are very rigid, nonportable and costly which is considered as a major drawback. The typical spirometer equipment used in the hospitals and laboratories consists of a mouthpiece interfaced to a PC. The aim of this paper is to design a portable handheld spirometer unit which is used for the measurement of lung parameters such as PEF (Peak Expiratory Flow), FVC (Forced Vital Capacity), and FEV1 (Forced Expiratory Volume in first second).The spirometer designed here is a portable unit interfaced along with a wireless Bluetooth module which communicates to an android enabled device. The graphical representations are transmitted wirelessly which indicates the physiological conditions related to the lungs are displayed. The Android compatible spirometer is to provide a portable access for the doctors and health experts to predict pulmonary disorders.
\end{abstract}

Keywords: Android, Spirometer, COPD, Bluetooth module.

\section{INTRODUCTION}

The most common and chronic disorder in children, affecting an estimate of about 6.2 million individuals of age group 18 is asthma [1]. The diagnosis and improvements in the field of asthma studies and its factors causing the disorder has been increased gradually over a span of 15 years. The major role of asthma as a disease is that it causes lung inflammation due to swelling of the airway duct which narrows the air into the lung tissues. The symptoms of asthma are coughing, wheezing, shortness of breath, and chest tightness. The factor behind these symptoms may be smoke or may be a genetic disorder. The prolonged condition of asthma due to negligence, will lead to COPD (Chronic Obstructive Pulmonary Disease).

COPD condition includes several lung diseases like emphysema and chronic bronchitis. The impact of COPD is the obstruction in the airway tract. The flow of air inhaled and exhaled in the lungs is less than ideal which means that the oxygen level should be maintained as per the requirement of the individual. In diseases such as chronic bronchitis, the lining of the breathing tube gets swollen, which in turn produces mucus and later is coughed up. Similarly, in emphysema the walls of alveolar sacs get broken down. There might be a condition wherein an individual might have both emphysema and chronic bronchitis. In fact, there are around 12 million people who have succumbed to COPD and roughly around 24 million who may possess and may not be aware of this disease [2]. A typical spirometer consists of various parts like mouthpiece, sensors, PC for study and display of the physiology of the lungs. There are various types of
Spirometers available in the market and it majorly depends on the type of sensors used. The relative and quick test for the study of lung parameters is supported with the aid of spirometer and its technique is often referred to as spirometry. The results from this technique are easy to access and readily available without much time delay. The standards for the minimum performance of the spirometer are based as per the guidelines of the American Thoracic Society (ATS) and European Respiratory Society (ERS) [3]. The aim of this paper is to reduce the cost of the mouthpiece here the mouthpiece is customized based on the requirement of the individual. A typical graphical representation of the lung capacity is given in the below figure [4].

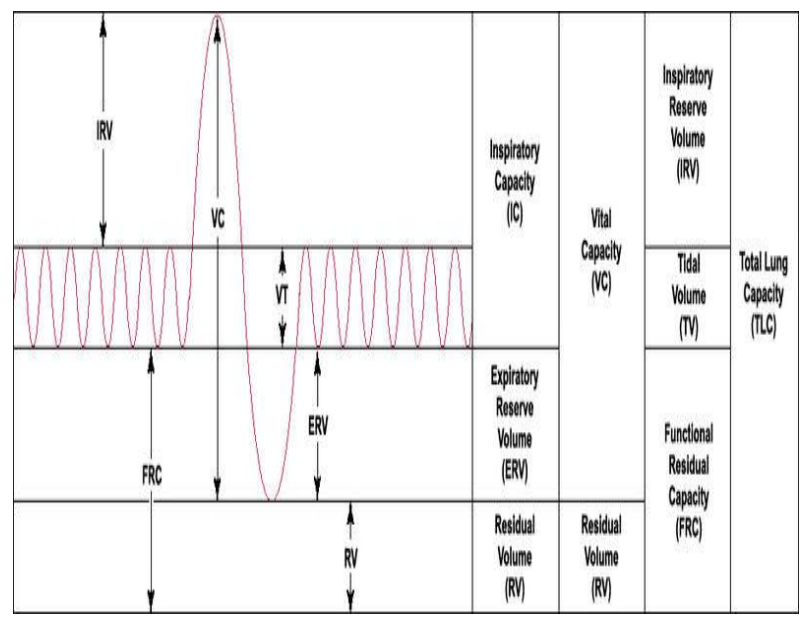

Fig -1: Graphical representation of waveforms for inhalation and exhalation in lungs for an individual 


\section{SPIROMETER ARCHITECTURE}

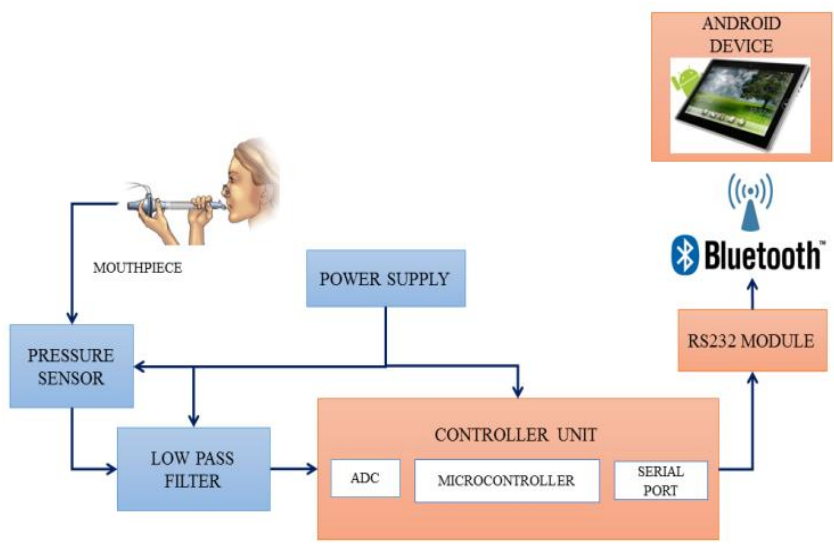

Fig -2: Block Diagram of Android device coupled Spirometer

The spirometer design is used to measure and study the physiology of the lungs. Here the patient is allowed to blow air in and out through the help of a mouthpiece with maximum effort. The spirometer design consists of a differential pressure sensor which measures and converts the pressure change into an electrical signal. These signals are filtered and processed by the microcontroller. The output from the microcontroller is then interfaced to an Android(C) device for easy access. The data are then studied, diagnosed and interpreted on the move by the pulmonologist for easier access.

The components used in this paper are classified into three sections: A) Design of mouthpiece along with the placement of the pressure sensor. B) Sensor interface to the microcontroller unit C) Wireless transmission of the controller output along with the interpretation of results on an Android device.

\section{SPIROMETER PROTOTYPE AND ITS} FUNCTION

\subsection{Design of Mouthpiece}

Before understanding the design of mouthpiece, let us consider the principle and working of a normal spirometer used in a healthcare facility.Fig. 1 provides the details of the individual's lung capacity and volumes. The types of waveforms obtained are very useful in the design of the mouthpiece. The mouthpiece designed here is used to calculate Forced Vital Capacity (FVC), Forced Expiratory Volume in first second (FEV1) and Peak Expiratory Flow (PEF) rate. Fig. 2 represents the model of the mouthpiece used for the development of the spirometer prototype. The mouthpiece connector is designed and is made up of a nylon rod. Further, this nylon rod is inserted onto a PVC (polyvinyl chloride) pipe. To obtain a maximum respiratory potential, an individual is asked to inhale and exhale through the mouthpiece. The total length of the mouthpiece connector is about $130 \mathrm{~mm}$ and its total diameter is of $46 \mathrm{~mm}$. The inner concentric hollow tube structure is made with different diameters. The pressure acting on the small diameter of about $28 \mathrm{~mm}$ is sensed by the sensor. The outer diameter of nylon rod is designed with $32 \mathrm{~mm}$ to facilitate connection of disposable mouthpiece. The outer region of the mouthpiece is connected to a pressure sensor to sense the respiratory variation.

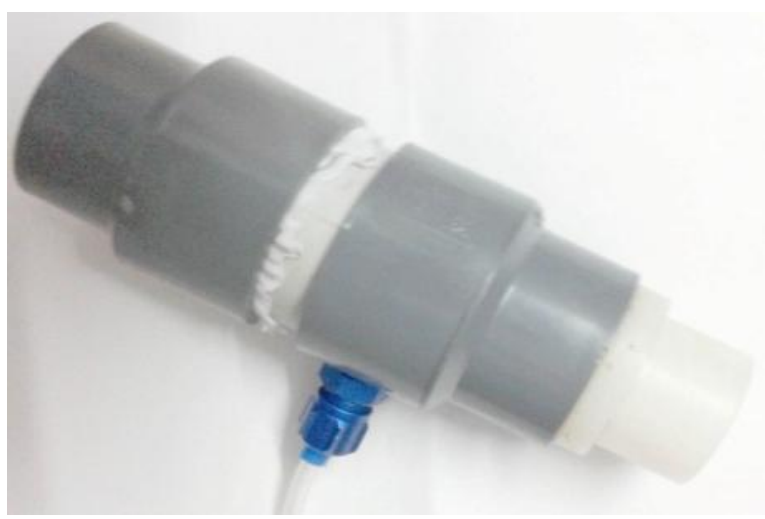

Fig -3: Design of mouthpiece connector

\subsection{Pressure Sensor}

A pressure sensor which is connected to the mouthpiece is a device which measures the changes in the pressure of gases and liquids. The working of the sensor is in such a way that the pressure of the liquid or gases causes the device to generate electrical signals. Previously, a differential pressure sensor was used [5]. Later, it was noticed that pressure sensor MPXV7002 satisfied the requirement. This sensor is a series of piezoresistive transducer in the small outline package (SOP), which is a state-of-the-art monolithic silicon pressure sensor. These pressure sensors give a reading relative to the normal pressure [9].

This sensor provides an accurate, high level analog output signal that is proportional to the applied pressure. It is also designed to measure positive and negative pressure. For reducing the effects of the sensor noise, a low-pass $\mathrm{RC}$ filter with a cut off frequency of $650 \mathrm{~Hz}$ is used.

\subsection{Mouthpiece Testing}

The mouthpiece is connected to a microcontroller along with the pressure sensor. The output from the microcontroller is given to the PC to obtain a plot for various values related to FVC, FEV1 and PEF are indicated in the Fig.3.The definitions of these parameters are given below.

1. FVC-The volume of air that can be blown out by an individual at a maximal speed and effort after a full inspiration.

2. FEV1-The maximum volume of air that can be exhaled in a forced way in the first second, after taking a deep breath.

3. PEF-The maximum air flow that can be forced during exhalation.

The pressure sensor is mounted at the center of the mouthpiece connector. The placement of the sensor lies between the connector and the inlet tube, which senses the variation in the pressure levels calculated through 
kilopascals. The mouthpiece is tested and compared along with the software provided by the Schiller spirometer unit, wherein the graphs are plotted with respect to FVC, FEV1, and PEF. Fig.4 represents the results of the plot obtained between the prototype and the Schiller's unit[5].

\subsection{Microcontroller}

PIC 16F8XX microcontrollers are RISC controllers with very small instruction set only of 35 instructions. PIC 16F887 is a 40-pin 8-bit CMOS FLASH microcontroller. It comes with three operating speeds with 4,8 or $20 \mathrm{MHz}$ clock input. It has two types of internal memories; one is program memory and another is data memory [11]. Program memory is provided by $8 \mathrm{~K}$ words of FLASH memory and a data memory has two sources.

\subsection{Bluetooth Module}

The output from the microcontroller is given serially to a Bluetooth module $\mathrm{HC}-05$, which wirelessly transmits the signal to android device. The HC-05 Bluetooth module supports SPP (Serial Port Protocol)and is designed for setting up a transparent wireless serial connection.

The serial port of the Bluetooth module is fully qualified with the latest version(Bluetooth V2.0+EDR Enhanced Data Rate) with the speed of $3 \mathrm{Mbps}$. The modulation frequency of a radio transceiver and baseband is around $2.4 \mathrm{GHz}$. The CSR Bluecore 04-External single chip Bluetooth system is used along with CMOS technology [7].

\section{TABULATION OF LUNG PARAMETERS}

The table 1 indicates the approximate values for obtaining a normal set of data for the age group from 18 till 65 years [8].

\section{RESULTS AND ANALYSIS}

The most important step in diagnosing abnormality of lung function in individuals is to define whether they are within or outside the healthy subjects range. For this purpose, the observed value of a patient is usually compared to a reference value obtained from prediction equations derived from studies on healthy people [10]. There are a few variables such as age, gender and body size which have an impact on the lung function of one individual compared to another. As a person ages, the natural elasticity of the lungs decreases. This translates into smaller and smaller lung volumes and capacities as we age. Body size has a tremendous effect on PFT values. A small man will have a smaller PFT result than a man of the same age who is much larger [12].

The graphical representation of the above table is plotted with respect to volume (Litres) in $\mathrm{X}$ axis and flow (Litres per second) in $\mathrm{Y}$ axis. Fig.4 indicates the normal set of values for the expected spirometer. The plot is obtained by inputting standard values from the terminal. Similarly, the plot for the prototype designed is also obtained and is represented in Fig.5.

1. Expected waveform of spirometer

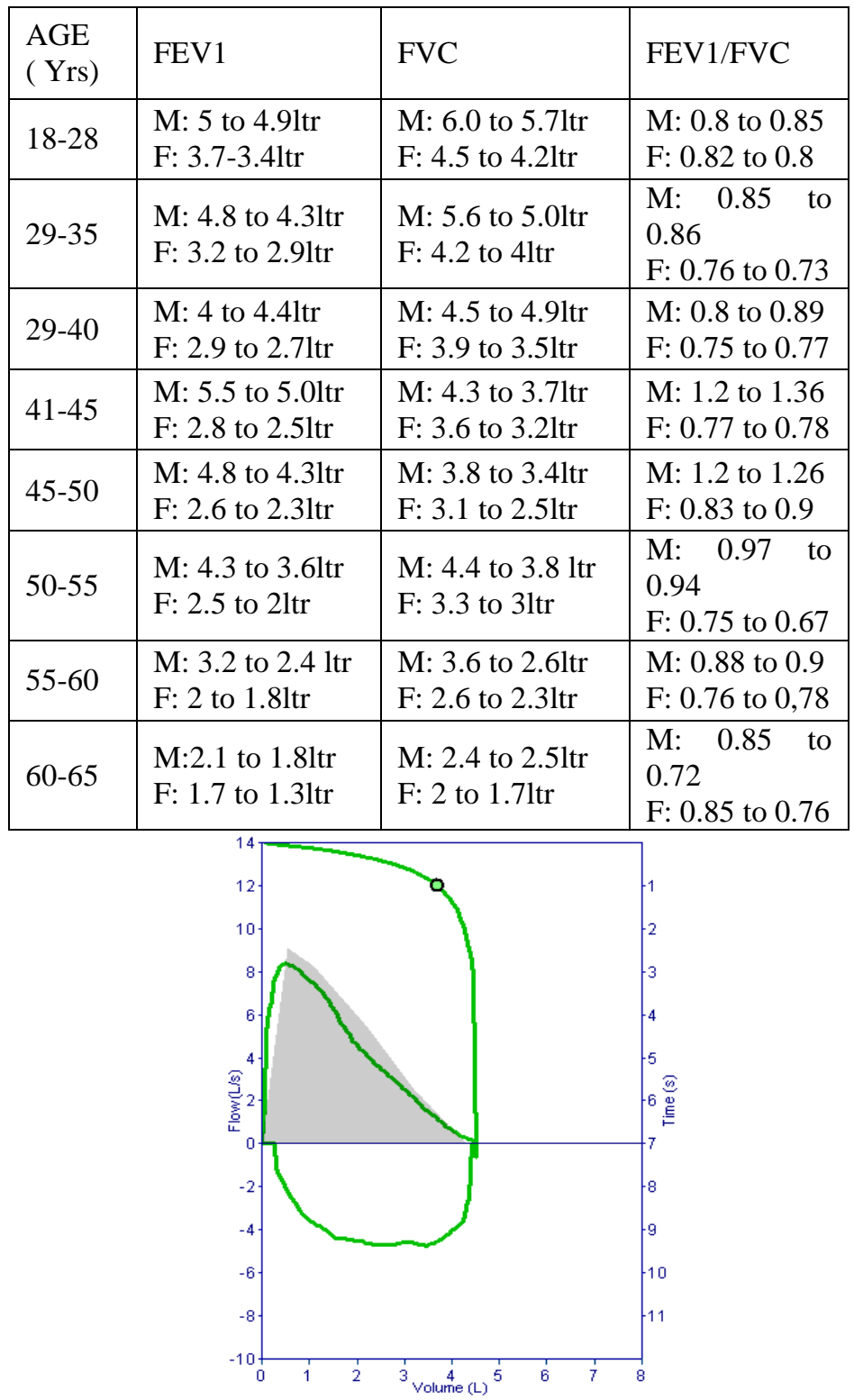

Fig -4: Normal spirometer values

2. Obtained waveform of the prototype designed

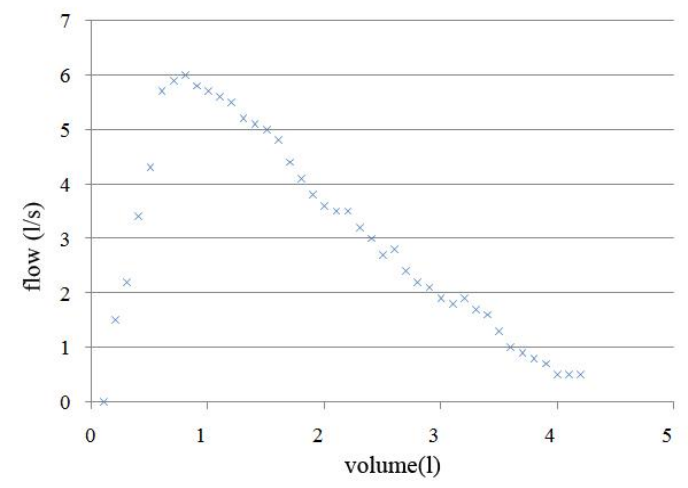

Fig -5: Obtained value in exhalation alone 
3. Android plot

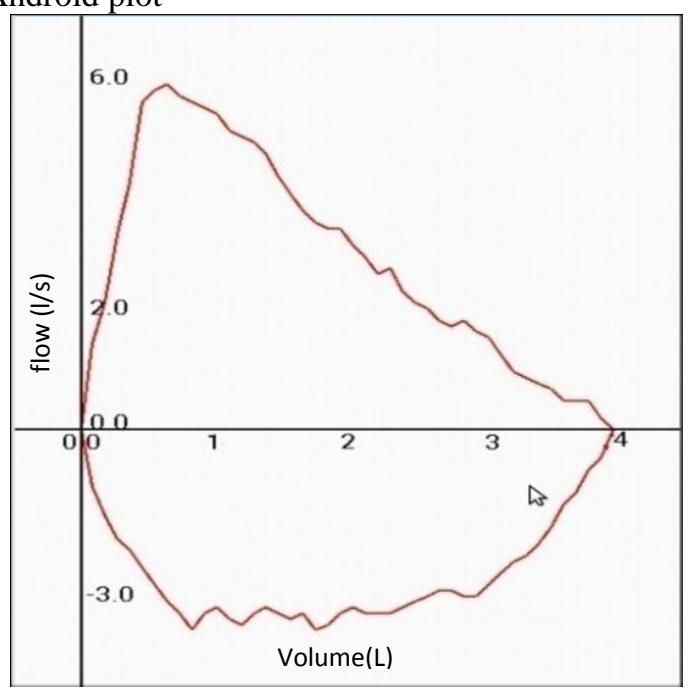

Fig -6: The Graphical plot used as a thumbnail in the of android user interface.

Table -2: Collected data comparison with standard spirometer

\begin{tabular}{|l|l|l|l|l|l|l|l|l|l|l|l|l|l|l|}
\hline \multicolumn{4}{|l|}{ Patient details } & \multicolumn{4}{l|}{ Predicted value } & \multicolumn{3}{l|}{ MIRspirobank output } & \multicolumn{3}{l|}{ Our designed spirometer output } \\
\hline $\begin{array}{l}\text { Age }(\mathrm{y} \\
\mathrm{r})\end{array}$ & $\begin{array}{l}\mathrm{Ht}(\mathrm{c} \\
\mathrm{m})\end{array}$ & $\begin{array}{l}\mathrm{Wt}(\mathrm{k} \\
\mathrm{g})\end{array}$ & $\begin{array}{l}\text { FV } \\
\mathrm{C}\end{array}$ & $\begin{array}{l}\text { FEV } \\
1\end{array}$ & PEF & $\begin{array}{l}\text { FEV1/F } \\
\text { VC }\end{array}$ & $\begin{array}{l}\text { FV } \\
\text { C }\end{array}$ & $\begin{array}{l}\text { FEV } \\
1\end{array}$ & PEF & $\begin{array}{l}\text { FEV1/ } \\
\text { FVC }\end{array}$ & FVC & $\begin{array}{l}\text { FEV } \\
1\end{array}$ & PEF & $\begin{array}{l}\text { FEV1/F } \\
\text { VC }\end{array}$ \\
\hline 10 & 34 & 25 & 1.83 & 1.61 & 4.05 & 90.3 & 1.18 & 0.91 & 1.42 & 77.1 & 1.15 & 0.83 & 1.4 & 72.17 \\
\hline 68 & 167 & 66 & 2.86 & 2.27 & 7.33 & 80.2 & 1.85 & 1.37 & 3.51 & 74.1 & 1.80 & 1.29 & 3.45 & 71.66 \\
\hline 22 & 173 & 76 & 4.30 & 3.71 & 9.09 & 85.7 & 4.35 & 3.53 & 8.42 & 81.1 & 4.31 & 3.40 & 8.40 & 78.8 \\
\hline 29 & 173 & 68 & 4.31 & 3.60 & 9.35 & 84.4 & 3.07 & 1.69 & 3.70 & 55 & 2.8 & 1.61 & 3.62 & 57.5 \\
\hline 42 & 161 & 39 & 3.09 & 2.58 & 7.67 & 84.2 & 0.85 & 0.63 & 1.76 & 74.1 & 0.78 & 0.60 & 1.65 & 76.9 \\
\hline 44 & 159 & 61 & 2.72 & 2.28 & 5.96 & 84.1 & 2.68 & 2.21 & 6.16 & 82.5 & 2.53 & 2.13 & 5.89 & 84.18 \\
\hline 46 & 162 & 70 & 2.80 & 2.33 & 6.05 & 82.9 & 2.89 & 2.21 & 6.36 & 76.5 & 2.82 & 2.12 & 6.23 & 74.9 \\
\hline 33 & 151 & 52 & 2.57 & 2.23 & 5.84 & 88.2 & 2.80 & 2.40 & 6.68 & 85.7 & 2.72 & 2.36 & 6.59 & 86.76 \\
\hline 48 & 143 & 52 & 2.04 & 1.75 & 5.07 & 87.1 & 2.10 & 1.60 & 3.78 & 76.2 & 1.95 & 1.57 & 3.70 & 80.51 \\
\hline 26 & 155 & 67 & 3.07 & 2.64 & 7.67 & 86.9 & 2.28 & 1.95 & 3.91 & 85.5 & 2.23 & 1.98 & 3.97 & 88.78 \\
\hline
\end{tabular}

\section{FUTURE SCOPE}

The prototype of spirometer design can further be enhanced by including more parameters such as Maximal voluntary ventilation (MVV), Slow Vital Capacity (SVC), Tidal Volume (TV) related to the lung function. Further, this prototype can be designed as a portable handheld device wherein a mouthpiece is connected to a mobile phone, tablet to interpret the result. This facility in future may help pulmonologists, nurses and medical practitioners in assisting and studying various pulmonary disorders. The clinical history related to various disorders can be developed as a database, which can be used as an add-on feature of the android application. The Global Positioning System (GPS) tracker is integrated onto the android application to provide the details related to nearest pulmonologist/hospitals/ laboratories for treatment. 
A separate database which includes age, height, and other medical information is added. The data for disease conditions of different pulmonary disorders are created and maintained for future reference [12]. The transmission

medium used for communication is further enhanced by using wireless technologies such as Zigbee, WiFi, WiMax.

\section{CONCLUSIONS}

The presentation of this paper deals with design and development of a low cost, highly feasible spirometer.The implementation of this prototype is executed through the design of a customized mouthpiece. With the help of this unit, the above mentioned conditions like asthma, COPD and other respiratory disorders may be diagnosed. This unit might be used to predict and control the progression of the above disorders. Finally the comparison between the actual spirometer and the obtained waveform of the prototype is plotted. The result of the prototype obtained slightly varies with the existing spirometer. The data obtained from this unit helps the pulmonologist and other health experts to study and analyze the reason behindthe cause for the obstructive/restrictive disorders.

\section{ACKNOWLEDGEMENTS}

The authors would like to acknowledge these individuals Dr. JaymohanUnnithan, Kovai Respiratory Care and Research Center for supporting this project. Assistant Professors S.Sandesh, M.Tech., Department of Bio-medical Engineering and A.Bharanidharan, M.E., Department of Computer Science Engineering at Sri Ramakrishna Engineering College who contributed equally as a team to this work in partial fulfillment of the requirements.

\section{REFERENCES}

[1]. Asthma and its environmental triggers - The National Allergen Survey," NIEHS (National Institute of Environmental Health Sciences), Research Triangle Park, NC 27709, US Department of Health and Human Services

[2]. Renee Klein"Research article on COPD and asthma," 300 Hour Yoga Therapy Program, July 2010.

[3]. Debbie Burton, David P.Johns, Maureen P.Swanney“'Spirometer's users and buyers' guide ," National Asthma Council Australia, Revised 2011, in press.

[4]. R.S.Khandpur, "Handbook of Biomedical Instrumentation,"2nd ed., Tata McGraw-Hill, 2007.

[5]. Antoinette Bumatay, Remy Chan, Keith Lauher et al, "Coupled mobile phone platform with peak flow meter enables real-time lung function assessment,"IEEE sensors journal, vol. 12, pp.685-691, March 2012

[6]. Schiller website.

Available:http://www.schiller.ch/Upload/

Spirometry_EN.pdf.

[7]. "HC-05 Datasheet" ITead Studio, Xili Town, NanshanDist, Shenzhen, China

[8]. Tomasz Gólczewski et al.: A mathematical reason for FEV1/FVC dependence on age, Respiratory Research 2012, $13: 57$
[9]. EngineersGarage, Pressure Sensors [Online] 2002. Available:http://www.engineersgarage.com/articles/pressure -sensors-types-working (Accessed: 15 February 2014) [10]. A.N.Aggarwal, Dheeraj Gupta, Digamber Behera and S.K.Jindal "Applicability of commonly used Caucasian prediction equations for spirometry interpretation in India," Indian J Med Res 122, August 2005, pp 153-164.

[11]. MikroElektronika, PIC Microcontrollers [Online]. Available: http://www.mikroe.com/chapters/view/2/chapter1-pic16f887-microcontroller-device-overview/ (Accessed: 20 December 2013)

[12]. Pulmonary Function Testing [Online]. Available: http://jan.ucc.nau.edu/daa/lecture/pft.htm (Accessed: 18 February 2014)

\section{BIOGRAPHIES}

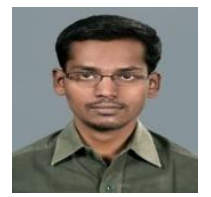

Karthikeyan.A, was born in Tamilnadu, India. Completed Diploma in Electronics and Communication Engineering from Government Polytechnic College, Coimbatore in 2007 and currently pursuing under graduate course, B.E. Biomedical Engineering in Sri Ramakrishna Engineering College, Coimbatore. His area of interest includes Endoscopy and Ultrasound.

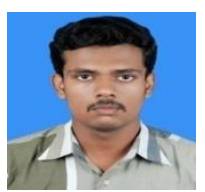

Khaleelu Rahman.M, originally from Kerala, India. Completed Diploma in Electronics and Communication Engineering from Sree Narayanaguru Polytechnic College, Coimbatore in 2011 and currently pursuing under graduate course, B.E. Biomedical Engineering in Sri Ramakrishna Engineering College, Coimbatore. His area of interest includes Medical instrumentation and Industrial Automation.

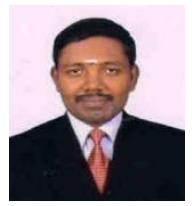

Velmurugan.A was born in Tamilnadu, India. He completed B.E. Electronics and Communication Engineering from Maharaja Engineering College, Avinashi and M.E VLSI from Karpagam University, Coimbatore in 1999 and 2013 respectively. Presently he is working as Assistant Professor at Sri Ramakrishna Engineering College, Coimbatore. His area of specialization includes VLSI Design, Biomedical Engineering- Radiology, and Endoscopy. 